\title{
Potential galactogogues effect of Silymarin: An experimental study in female rats
}

\author{
B. I. Mohammed \\ Coll. of Pharmacy-Univ. \\ Al-Qadissiya \\ jumabassim@yahoo.co.uk
}

\author{
H. A. Alzamily \\ Coll. of Vet.- Univ. of \\ ALQasim green
}

F. Kh. Jassim

privet sector

\begin{abstract}
The study aimed to evaluate the galactogogues effect of Silymarin in pregnant and lactating female rats. A total of 72 pregnant female Wistar rats randomly divided into 3 groups ( 24 rats of each). Rats in first group used as control, received drinking water daily for 14 days from 8th day of gestation till the delivery, while the animals in second group, received Metoclopramide ( $5 \mathrm{mg} \mathrm{kg} \backslash \mathrm{lday}$ ) as the same period. In addition to Silymarin group (treatment group) received Silymarin (200 mglkglday) as the same period. Dams' body weights have been monitored throughout the pregnancy. At the first day of parturition, litter weights have been measured, and (8) animals of each groups were sacrificed, blood sample were collected to measure the serum prolactin level. In addition, the litters were allocated in to (8) litters per lactated dam. Then each group sub divided in to two sub groups A and B according to continue or discontinue of received drugs, for 11days from parturition. Silymarin in a dose $(200 \mathrm{mg} \backslash \mathrm{kg}$ ) was significantly increase litters body weight and serum prolactin level in pregnant female rat $(\mathrm{p}<0.05)$ in compared with control and Metoclopramide groups. Silymarin and Metoclopramide during the eleventh day of lactation registered significant differences $(\mathrm{P}<0.05)$ in their serum prolactin concentration, litters weight gain compared with that stopped in receiving the treatment in the same group, whereas control subgroups revealed no significant $(\mathrm{P}>0.05)$ differences when compared with each other. It can be concluded that Silymarin has potential glactogoguse effect and enhance milk production.
\end{abstract}

Key words: Silymarin, prolactin, galactogogues and milk production.

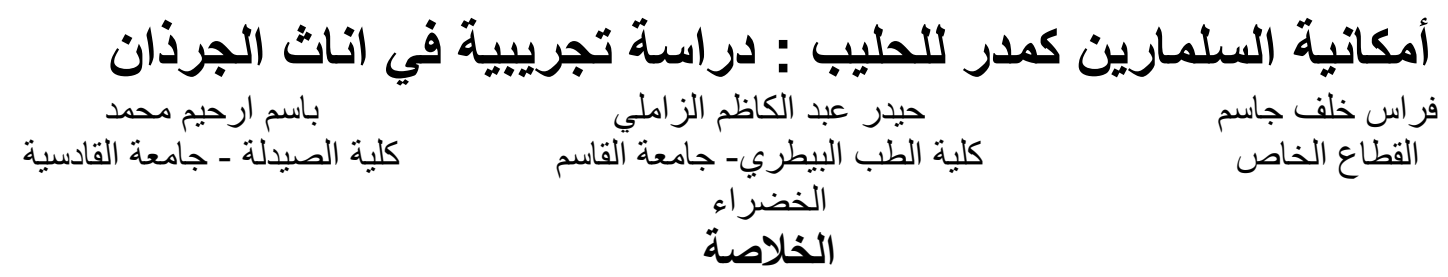

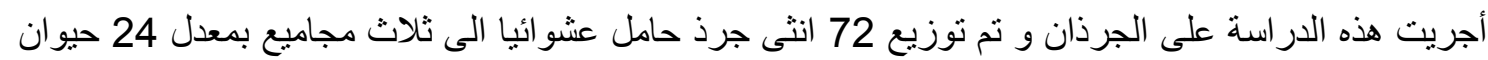

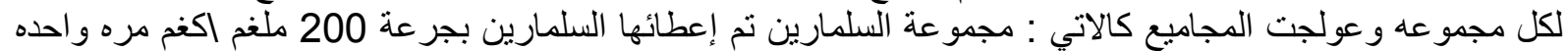

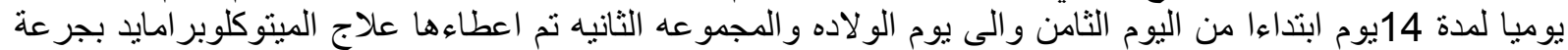

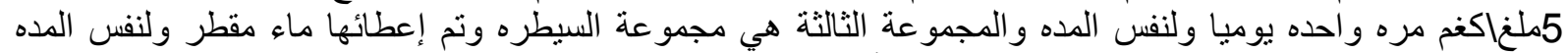

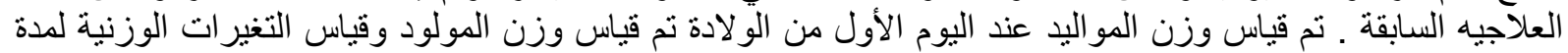

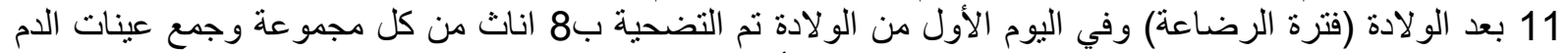

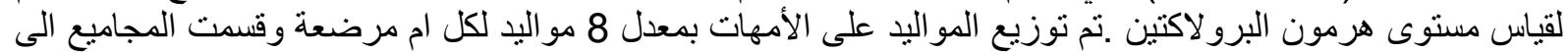

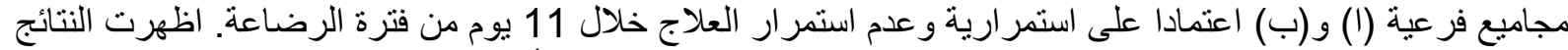

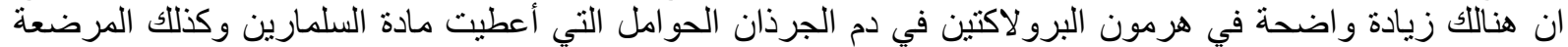

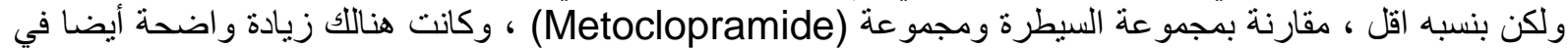

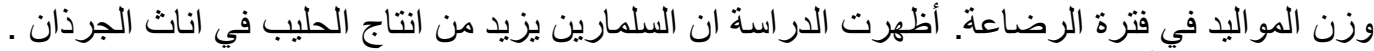

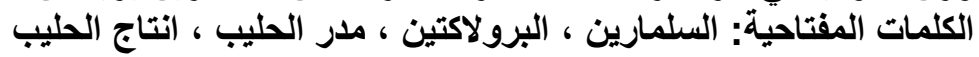

\section{Introduction}

The livestock is essential national and international economic tributary and the milk is one of the economic importance animal productions because is essential substance in neonatal feeding till to weaning and provide the kid by immunoglobulin. In addition the importance in human nutrition from directs consumption using in various nutritional industries. Studies indicated to the animal production in general and milk industries in specials are essential and economic imports 
for more of developed nation in the world. Therefor the milk industries in these countries have a great importance to the concerned through the preparation of a long term programs for the development and care of livestock and conducting researches and scientific studies that would increase milk production. (1).A number of herbal plants, which contain large number of chemical active principles including alkaloids, having galactogenic properties, can be used as herbal medicine for the purpose of milk let-down in milking animals. Among of these, Milk thistle (Silbanum marianum), Mother's milk tea and Ashwagandha and Shatavari plant ingredients have been emphasized in Ayurveda. Their inclusion in veterinary medicine as herbal galactogogues needs thorough and critical evaluation (2).

\section{Milk thistle's}

(Silybum marianum) common name comes from the white markings on the leaves, its milky white sap, and its traditional use by nursing mothers to increase milk. But it is best known for its use as a liver protectant and decongestant, which can be traced to the Greeks and Pliny the Elder (2379AD), who wrote that it was excellent for "carrying off bile." The famous English herbalist Culpepper (1616-1654) used milk thistle to cleanse the liver and spleen, and to treat jaundice and gallstones (3). The main active principles contained in milk thistle are silybin (silibinin), sylichrisitn and silydianin, commonly referred to collectively as Sylimarin (4,5). Silymarin is a unique flavonoid complex containing silybin, silydianin, and silychrisin, that is derived from the milk thistle plant. These unique phytochemicals from the milk thistle have been the subject of decades of research into their beneficial properties (6). Therefore, the present study was designated to evaluate the galactogogues effect of Silymarin in pregnant and lactating female rats.

\section{Materials and methods}

Preparation of animals:

A total one hundred twenty Mature Wistar albino rats (80 female and 40 male) with a mean weight of $180 \pm 20 \mathrm{~g}$, obtained from the animal house at the College of Veterinary Medicine, Al Qadisiya
University. All animals were kept in isolated room and maintained on controlled conditions (temperature $20-25 \mathrm{C}^{\circ}$, humidity $30-70 \%$ and alternating light and dark $12 \mathrm{~h}$ dark/light cycle). The animals had free access to chow diet and water ad libitum. After 2 weeks of acclimatization and estrus synchronization period, Mating was performing by keeping the animals in a group caging system (two female and one male rat) for 3 days.

\section{Experimental design:}

Seventy-two pregnant female rats were randomized into three equal group ( 24 rats each), and the animals were treated in the pregnancy period as following: Control group (C) received drinking water once daily for 14 days starting from 8th day of gestation until the delivery. Metoclopramide group (M) received Metoclopramide (5mglkg $\backslash$ day) for 14 days from 8th day of gestation until the delivery. Silymarin group (S) received Silymarin (200 mglkglday) for 14 days from 8th day of gestation till the delivery. After parturition, litters' weight was measured (first day weight). Then eight animals from each group have sacrificed to obtained blood sample. The rest animals (16 rats per group) were further subdivide in to two equal subgroups. In addition, the litters were allocated in to (8) litters per lactated dam,(7) . The groups :(CB) received drinking water, (CA) group received Silymarin (200mglkglday), (MA) group continue with metoclopramide treatment (5mglkglday), (MB) group continue without metoclopramide treatment, (SA) group continue received Silymarin (200mglkglday) and (SB) group continue without Silymarin for 11 days from parturition (lactation period)(7). At the 11th day of lactation, the lactated dams were sacrificed to obtain the blood samples.

\section{Drugs:}

Metoclopramide oral drops were purchased from Julfar company (UAE) at the dose $(5 \mathrm{mg} / \mathrm{kg} /$ day $)(8,9)$. Milk thistle seed extract (Silymarin) oral drops were purchased from Natures answer manufacturers for herbal extract (USA) in a 
dose of $200 \mathrm{mg} / \mathrm{kg} /$ day orally by stomach tube (10)

\section{Preparation samples:}

From each rat, $4 \mathrm{ml}$ of blood were collected from the abdominal vein, by using disposable syringe under general anesthesia (Ketamine $90 \mathrm{mg} \mathrm{kg}$ and Xylazine $10 \mathrm{mg} \mathrm{kg}$, IP) (11), one ml of serum was collected and used for assessment of serum prolactin hormones using ELISA technique.

\section{Assessment of study parameters}

Measurement of litters' body weight:

This test was used to measure the weighted changes in litters' body weight by using sensitive balance. Litters body weight was measured at first day of parturition and then daily until to 11th day of lactation period.

Assessment of serum prolactin level.

According to the manufacturer instructions Serum prolactin levels were analyzed using ELISA that purchased from ABO Company Switzerland.

\section{Statistical analysis}

All the values are expressed as mean \pm SEM. Data of the experiment were analyzed using one way analysis of variance (ANOVA
1), using F-test, regression analysis, and correlation coefficient (12). Least significant difference; LSD was carried out to estimate the significance of difference between individual groups. $\mathrm{P}$ value less than 0.05 was considered significant.

\section{Results}

\section{Litters' Body weight:}

At the first day after parturition, litters of Silymarin treated groups recorded significant $(\mathrm{P}<0.05)$ higher weight among experimental groups. On the other, litter weight of Metoclopramide treated group was significantly $(\mathrm{P}<0.05)$ higher that that recorded in control (figure 1). During the eleventh day of lactation, cumulative litter weight gains were significantly $(\mathrm{P}<0.05)$ high in Silymarin and Metoclopramide treated groups compared with that of control. On the other hand, lactating female rats that continued in receiving Silymarin and Metoclopramide registered significant differences $(\mathrm{P}<0.05)$ compared with that stopped in receiving the treatment in the same group, whereas control subgroups revealed no significant difference $(\mathrm{P}>0.05)$ when compared with each other (figure 2).

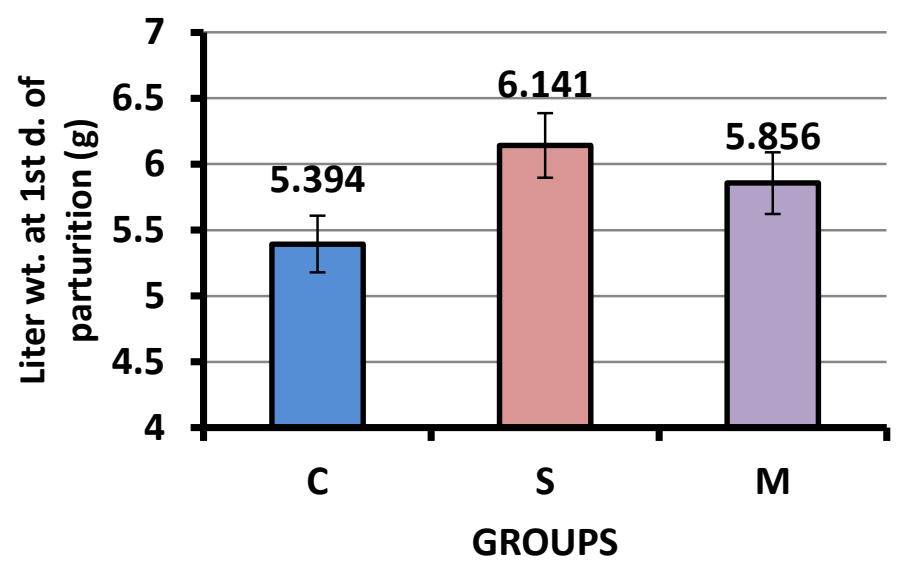

Figure (1): effect of oral administration of Silymarin during 2nd and 3rd stages of pregnancy in female rats on litter weight (g) at the 1st day after parturition.

Numbers represent $\mathrm{M} \pm \mathrm{SE}$. C: litters of control rats received drinking water (po) during 2nd and 3rd stages of pregnancy. S: litter of rats received Silymarin (po) $(200 \mathrm{mg} / \mathrm{kg}$, bw) during 2nd and 3rd stages of pregnancy. M: litter of rats received Metoclopramide (po) $(5 \mathrm{mg} / \mathrm{kg}$, bw) during $2 \mathrm{nd}$ and $3 \mathrm{rd}$ stages of pregnancy. 


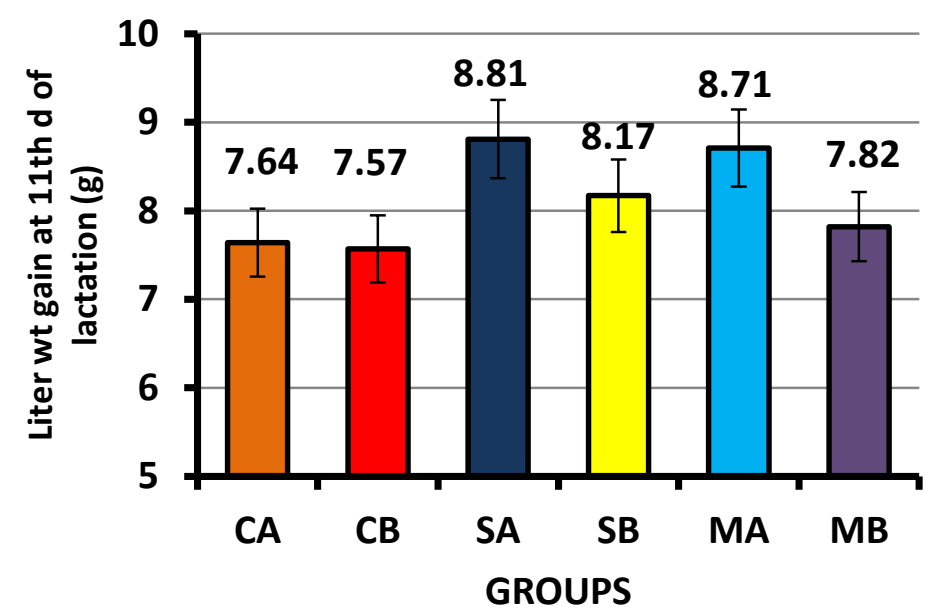

Figure (2): effect of oral administration of Silymarin during 2nd and 3rd stages of pregnancy in female rats on final litters' weight gain (g) at the 11th day of lactation.

Numbers represent $\mathrm{M} \pm \mathrm{SE}$. CA: control rats received Silymarin from parturition to 11th day of lactation. CB: control rats received drinking water from parturition to 11 th day of lactation. MA: rats received metoclopramide from parturition to 11th day of lactation. MB: rats discontinued receive metoclopramide from parturition to 11th day of lactation. SA: rats received Silymarin from parturition to 11th day of lactation. SB: rats discontinued receive Silymarin from parturition to 11th day of lactation

\section{Serum prolactin level:}

Results of serum prolactin level, illustrated in figures (3), revealed significant elevation $(\mathrm{P}<0.05)$ in Silymarin and Metoclopramide treated groups compared with control group, at the first day after parturition. On the other hand, lactating female rats, that continued in receiving
Silymarin and Metoclopramide during the eleventh day of lactation, registered significant differences $(\mathrm{P}<0.05)$, in their serum prolactin level, compared with that stopped in receiving the treatment in the same group, whereas control subgroups revealed no significant $(\mathrm{P}>0.05)$ differences when compared with each other (figure 4).

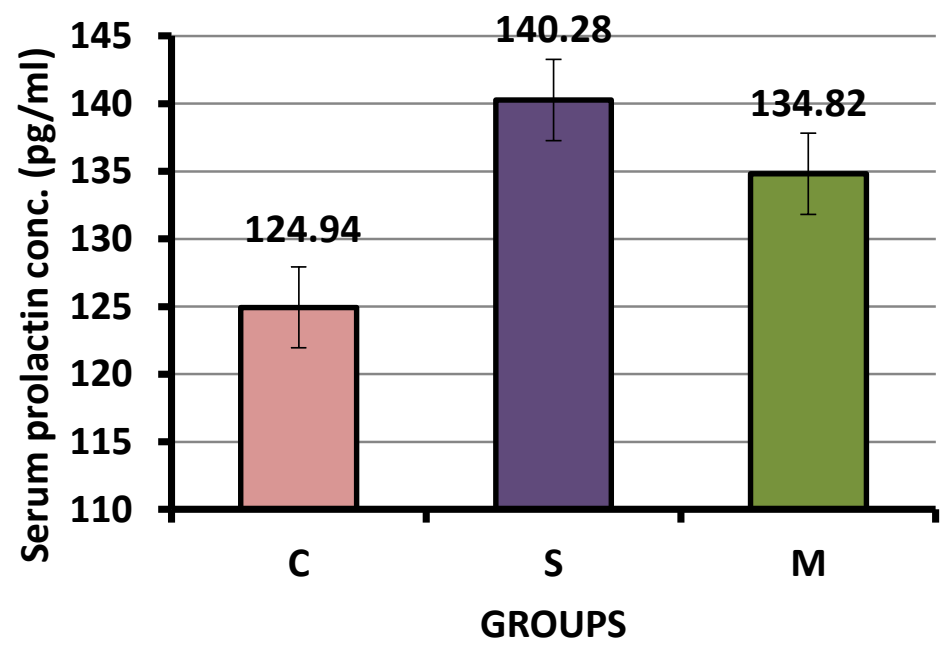

Figure (3): effect of oral administration of Silymarin during 2nd and 3rd stages of pregnancy in female rats on serum prolactin concentration $(\mathrm{pg} / \mathrm{ml})$ at the 1 st day after parturition. Numbers represent $\mathrm{M} \pm \mathrm{SE}$. Stars represent significant difference $(\mathrm{P}<0.05)$ compared with control.

Numbers represent $\mathrm{M} \pm \mathrm{SE}$. C: litters of control rats received drinking water (po) during 2nd and 3rd stages of pregnancy. S: litter of rats received Silymarin (po) $(200 \mathrm{mg} / \mathrm{kg}$, bw) during 2 nd and 3rd stages of pregnancy. M: litter of rats received Metoclopramide (po) $(5 \mathrm{mg} / \mathrm{kg}$, bw) during $2 \mathrm{nd}$ and $3 \mathrm{rd}$ stages of pregnancy. 


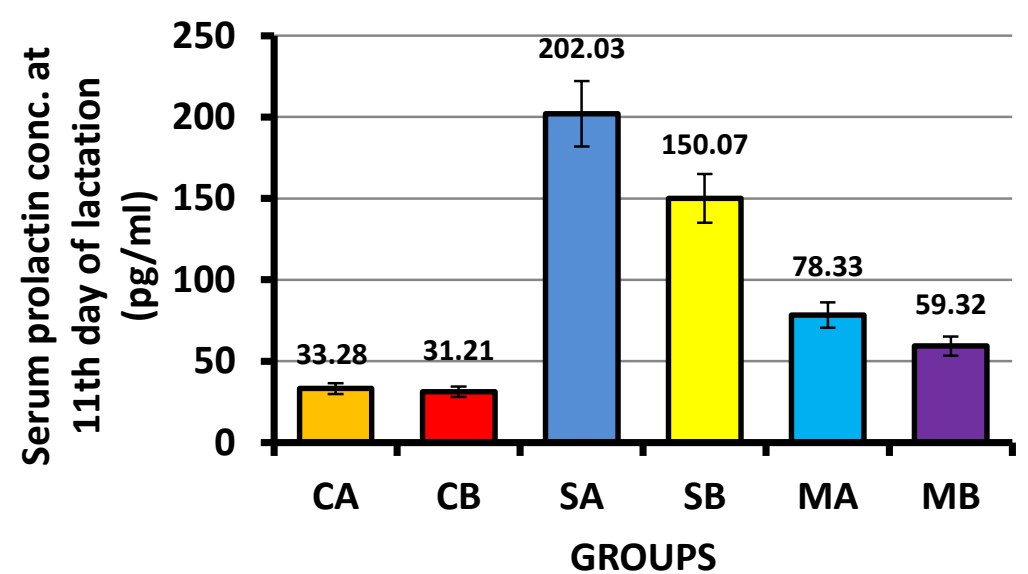

Figure (4): effect of oral administration of Silymarin during 2nd and 3rd stages of pregnancy in female rats on serum prolactin concentration $(\mathrm{pg} / \mathrm{ml})$ at the 11 th day of lactation.

Numbers represent $\mathrm{M} \pm \mathrm{SE}$. Stars represent significant difference $(\mathrm{P}<0.05)$ compared with control. CA: control rats received Silymarin from parturition to 11th day of lactation. CB: control rats received drinking water from parturition to 11th day of lactation MA: rats received metoclopramide from parturition to 11th day of lactation. MB: rats discontinued receive metoclopramide from parturition to 11th day of lactation. SA: rats received Silymarin from parturition to 11th day of lactation. SB: rats discontinued receive Silymarin from parturition to 11th day of lactation

\section{Discussion}

\section{Effect of Silymarin on litters body weight} gain:

In this study, we noticed that Silymarin increase the activity of mammary gland and thus milk production as evidenced indirectly by the increment in the litters' body weight.

Effect of Silymarin on serum prolactin level:

Number of botanical remedies (e.g anise, fennel fenugreek seed, nettle and milk thistle seed) have been traditionally used to stimulate milk production (13). The observation that, an extract of milk thistle seed increase lactation in cows (14) and women (15) has gained renewed interest in its galactogenic properties. However the mode of action of milk thistle is still elusive (10). In the present study we have demonstrated that silymarin increase serum prolactin level in pregnant and lactated female rats too more importantly we have shown in metoclopramide and control group. Moreover, female rats that continue to received Silymarin from pregnancy to 11 th day after parturition (lactation period), showed significant increase in serum prolactin compared to these discontinue administration of Silymarin after parturition, and compared with female rats that administrated Silymarin from parturition until to 11th day of lactation. By this result could be explain the positive effect of Silymarin on serum prolactin started from pregnancy and continue throughout the lactation. This agreement with mammogenesis processes (The major portion of mammary growth occurs during pregnancy and is controlled by hormones.

Growth of the mammary gland is slow at the beginning of pregnancy, but the rate of growth accelerates as the pregnancy advances. Mammogenesis during pregnancy has been shown to be exponential in cattle goats and guinea pigs (16). Thus prolactin and placental lactogen, which bind to prolactin receptor, act during three stages: lobulo budding during organogenesis, lobuloalevoler expansion during pregnancy, and lactational differentiation and maintenance milk secretion during lactation (17). Prolactin hormone produced by the pituitary gland enhance two activities in the mammary gland such as stimulation of mammary gland growth during pregnancy and stimulation of milk production while nursing infant $(18,19)$. Therefore, drugs stimulating prolactin production are generally used to enhance milk production (20). Our experiment have shown Silymarin similarly to metoclopramide (drug have galactogenic properties) increase serum 
prolactin level in female rats pregnancy and lactation. These results could support the notion that the increment in milk production previously observed in cow and human $(14,15)$.

\section{References}

1. Bath, D.L., Dickerson, F.N., Tuker, H.A. and Appleman, R.D. (1985): Dairy cattle: principle practices problems, protits (3'd edition). Lea and Febiger. Philadelphia.

2. Mishra, U.K., Kanesh, J.S., Mandal, A.K., Das, R.K., Rayaguru, K. and Parija, S.C. (2006) :Potentials of herbal galactogogues in milk production of ruminants. The Indian Cow. JulySept: 44-52.

3. Presser, Arthur.,(2000): Pharmacist's Guide to Medicinal Herbs. Smart Publications, Petaluma, CA, 2000.pp 259-260.

4. Boon H, Smith M.,(2004): The Complete Natural Medicine Guide to the 50 Most Common Medicinal Herbs 2 nd ed. Toronto: Robert Rose; 2004; pp.214-218.

5. Blumenthal, M. (2003): The ABC Clinical Guide to Herbs. New York: Thieme;; pp.285-295.

6. Valenzuela, A.Garrido, (1994): Biochemical bases of the pharmacological action of the flavonoid silymarin and of its structural isomer silibinin. Biol. Res. 27: 105-112.

7. DeSantiago, S., Torres, N., Suryawan, A., Tovar, A. R. \& Hutson, S. M. (1998): Regulation of branched-chain amino acid metabolism in the lactating rat. J. Nutr. 128: 1165-1171.

8. Gaya, I.B., Okasha, M.A.M., Abubakar, M.S., Maje, M.I. and Adebayo, B.A. (2012): Toxicological and lactogenic studies on the seeds of Hibiscus sabdariffa linn (Malvaceae) extract on serum prolactin levels of albino wistar rats. The Internet Journal of Endocrinology. 5(2): 46-50.

9. Okasha. M. A. M; Abubakar. M. S; Bako. I. G,(2008): Study of the Effect of Aqueous Hibiscus Sabdariffa Linn Seed Extract on Serum Prolactin Level of Lactating Female Albino Rats. European Journal of Scientific Research ISSN 1450-216X Vol.22 No.4, pp.575-583.

10. Capasso R, Aviello G, Capasso F, Savino F, Izzo Angelo A and Borrelli F, (2009): Silymarin BIO$C \circledR$, an extract from Silybum marianum fruits,

\section{Conclusion and Recommendation:}

we can conclude that Silymarin has potential glactogoguse effect and enhance milk production. Further studies should be directed towards detailed of mRNA expression level of prolactin and prolactin receptor genes in pituitary and mammary glands of pregnant and lactating female rats.

induces hyperprolactinemia in intact female rats. Department of Experimental Pharmacology, University of Naples Federico II, Naples, Italy. Phytomedicine, 16, 839-844.

11. Patrick, E. Sharp, Marie C. La Regina, and Mark A. Suckow. (1998): The Laboratory Rat. N.p.: CRC, Print.

12. Schefler, W. C. (1980): Statistics for the Biological Sciences (2nd edition). AddisonWesley.

13. Capasso, F., Gaginella, T.S., Izzo, A.A., Grandolini, G., (2003): Phytotherapy. A Quick Reference to Herbal Medicine. Springer, Berlin and Heidelberg GmbH \& Co. K.

14. Tedesco D, Domeneghini C, Sciannimanico D, Tameni M, Steidler S, Galletti S,(2004b): Silymarin, a possible hepatoprotector in dairy cows: biochemical and histological observations. Journal of Veterinary Medicine Serie A , 51 (2), 85-89.

15. Carotenuto, D., Di Pierro, F., (2005): Studio sulla tollerabilita ed efficacia della silimarina BIOC [R] (Piulatte [R]) micro-nizzata come galattagogo. Acta Neonantol. Pediatr. 4,393-400.

16. Martinet j. H. Head, L. Houdebine (1999): biology of lactation, pages 342-460B.

17. Horseman ND.,(1999): Prolactin and mammary gland development. Journal of Mammary Gland Biol Neoplasia. 1999 Jan;4(1):79-88.

18. Grattan, D.R., (2002): Behavioural significance of prolactin signalling in the central nervous system during pregnancy and lactation. Reproduction 123 , 497-506.

19. Ben-Jonathan, N., Hugo, E.R., Brandebourg, T.D., LaPensee, C.R., (2006): Focus on prolactin as a metabolic hormone. Trends Endocrinol. Metab. 17, 110-116.

20. Gabay, M.P., (2002): Galactogogues: medications that induce lactation. J. Hum. Lact. 18, 274279. 